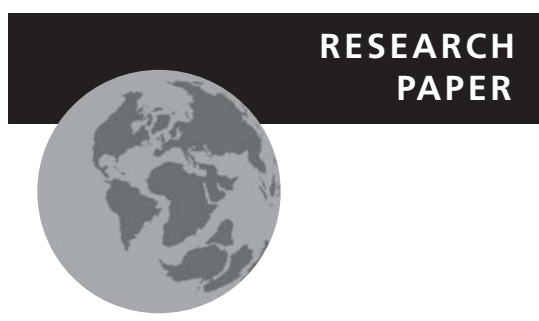

\title{
Incorporation of plant traits in a land surface model helps explain the global biogeographical distribution of major forest functional types
}

Xingjie Lu ${ }^{1 \star}$, Ying-Ping Wang ${ }^{1}$, Ian J. Wright ${ }^{2}$, Peter B. Reich ${ }^{3,4}$, Zheng Shi ${ }^{5}$ and Yongjiu Dai ${ }^{6}$

${ }^{1}$ CSIRO Ocean and Atmosphere Flagship,

Private Bag 1, Vic. 3195, Australia,

${ }^{2}$ Department of Biological Sciences,

Macquarie University, NSW 2109, Australia,

${ }^{3}$ Department of Forest Resources, University

of Minnesota, St Paul, MN 55108, USA,

${ }^{4}$ Hawkesbury Institute for the Environment,

University of Western Sydney, Penrith, NSW

2751, Australia, ${ }^{5}$ Department of

Microbiology and Plant Biology, University

of Oklahoma, Norman, OK 73072, USA,

${ }^{6}$ School of Atmospheric Sciences, Sun Yat-sen

University, Guangzhou, Guangdong 519082,

China

${ }^{\star}$ Correspondence: Xingjie Lu, CSIRO Ocean and Atmosphere Flagship, Vic. 3195,

Australia.

E-mail: chris.lu@csiro.au

\begin{abstract}
Aims Contrasting leaf types with different leaf life spans represent different adaptive strategies in plants. Previous studies explained the adaptive advantages of different strategies on the basis of environmental climatic limits, but could not account for the observed co-dominance of multiple plant functional types (PFTs) in many regions. Here we used a process-based model to explore whether observed inter- and intra-PFT variation in plant traits can explain global biogeographical variation in the dominance and co-dominance of major forest types.
\end{abstract}

Location World-wide.

Methods We identified four important plant traits: leaf $\mathrm{N}$ concentration, leaf life span, fraction of net primary production (NPP) allocated to leaves and plant basal respiration rate. We incorporated means and variances of these plant traits from trait databases into the Community Atmosphere-BiosphereLand Exchange model. We then predicted the dominant PFT or PFT mixture for global forested grid cells, using NPP as a proxy for growth rate, and considering three PFTs: evergreen needleleaf forests (ENF), evergreen broadleaf forests (EBF) and deciduous broadleaf forests (DBF). We compared results with: (1) those from simulations that did not account for trait variance; (2) results from an empirical model based purely on mean annual temperature; and (3) data from remotely sensed observations.

Results Our estimates of the fractions of land area covered by major forest types were consistent with observation; i.e. ENFs dominate in boreal regions, EBFs dominate in tropical regions and DBFs are distributed widely across a broad range of environmental conditions. We also showed that co-dominance of different forest PFTs cannot be reproduced without considering variation in plant traits.

Main conclusions Global trait data are useful for representing underlying plant strategies and functional diversity. Variation in key plant traits explains significant fractions of global biogeographical variation of three major forest types. Future developments in dynamic global vegetation modelling will benefit from the inclusion of plant trait variation.

\section{Keywords}

Ensemble simulations, global biogeography, plant functional types, plant strategy, plant traits, trait continua based modelling. 


\section{INTRODUCTION}

Understanding the global biogeographical patterns of different vegetation types has interested scientists well for over a century (Schimper et al., 1903; Warming et al., 1909; Givnish, 2002; Bond et al., 2005; Elith \& Leathwick, 2009). It is generally accepted that both climate and soils have major influences on the biogeographical patterns of needleleaf versus broadleaf species and evergreen versus deciduous species (Reich et al., 1992). Needleleaf trees are generally thought to be equally or better adapted to cold or nutrient-poor environments than broadleaf trees (Bond, 1989), while broadleaf species are more successful competitors in wet tropical regions (Givnish, 2002).

On average, evergreen and deciduous, needleleaf and broadleaf tree species differ in many physiological, structural and reproductive characteristics; for example, leaf nitrogen concentration, leaf life span, leaf mass per area, lightsaturated photosynthetic rate per unit leaf nitrogen (Reich et al., 1997; Wright et al., 2004); wood density and vascular properties (Bond, 1989; Choat et al., 2011) and in the relative dominance of wind versus insect pollination within these species groups (Crepet, 1984). These differences are believed to directly or interactively affect biogeographical patterns. Previous analyses have shown how plant traits affect the distribution of plant functional types (PFTs), but the exact relationships are still difficult to define (Kikuzawa, 1991; Givnish, 2002). Meanwhile, both top-down and bottom-up models have been put forward to simulate the observed global biogeographical patterns of different forest types. Topdown models constrain vegetation-type distributions based on empirical assumptions about the tolerance of plants to temperature and moisture stresses (Prentice et al., 1992; Haxeltine \& Prentice, 1996). These models are usually developed and applied using a spatially explicit approach, and can therefore be calibrated using independent estimates such as satellite observations (Givnish, 2002), but the underlying mechanisms are not explicitly represented in this approach. By contrast, bottom-up approaches quantify the competitiveness or fitness of different vegetation types using net carbon production simulated by relatively simple models (Bond, 1989; Kikuzawa, 1991, 1995; Givnish, 2002; McMurtrie \& Dewar, 2011). The bottom-up approach has been used to explain the distribution patterns of vegetation types, and has helped us gain insights into the mechanisms of competition among different vegetation types (i.e. PFTs). However the bottom-up approach is not usually applied globally in a spatially explicit manner.

Many bottom-up approaches use net primary productivity (NPP) as a proxy for growth rate. NPP is calculated as the difference between photosynthesis and respiration at an ecosystem scale (i.e not at the leaf or individual scale). The rates of photosynthesis and respiration depend on the environmental conditions in which plants grow and their key plant traits. These factors underpin a spectrum of 'leaf economic' strategies that can be discerned among plant species (Reich et al., 1997; Wright et al., 2004). At one extreme there are species with 'fast-return' strategies, often in very productive micro-habitats, involving short leaf life span, low leaf mass per area (low per-leaf-area construction costs) and high mass-basis leaf photosynthetic capacity (therefore fast returns on investments), for example many deciduous broadleaf species and many herbaceous species. At the other extreme, often in cold, nutrient-poor or dry habitats, there are species with 'slow-return' strategies involving a long leaf life span, high leaf mass per area and low photosynthetic capacity (Wright et al., 2004), for example many evergreen needleleaf species (Reich et al., 1997). Presumably, both fast and slow strategies trade off the benefit (photosynthesis) and the cost (maintenance and respiration) to maximize their survival rate and reproduction in order to achieve maximal growth rate under given conditions. This is a key assumption made in many previous studies, and also in this study (Bond, 1989; Kikuzawa, 1991, 1995; Givnish, 2002; McMurtrie \& Dewar, 2011).

One approach to represent these costs and benefits is to use dynamic global vegetation models (DGVMs), which are mainly based on bottom-up approaches (Bonan et al., 2003; Sitch et al., 2003, 2008). In most of those models, global vegetation is represented by a number of PFTs and plant traits are incorporated as single parameter values for each PFT. The outcome of competition among different PFTs under a given condition depends on establishment, survival, growth, competition, disturbance and mortality. In the absence of fire or other disturbances, the simulated global distributions of different forest PFTs by DGVMs will usually be dominated by one PFT at any location, because only one PFT has the highest NPP at any given location - and therefore the maximum growth rate. However, in reality, many areas are codominated by more than one PFT. The inability of current DGVMs to simulate the co-dominance of multiple PFTs may result from the use of single trait values to represent each PFT. Observations show that many key plant traits used in the process-based models vary as widely within individual PFTs as the mean differences among them (Reich et al., 1997; Wright et al., 2004; Kattge et al., 2011). Variation within PFTs represents both interspecific and intraspecific trait variation.

In this study we use a bottom-up model, the Community Atmosphere-Biosphere-Land Exchange (CABLE) model (Wang et al., 2010, 2011; Kowalczyk et al., 2013), to estimate the fractions of global land area covered by different forest functional types, via their NPP. We used an ensemble-based approach that allowed us to take account of trait variation among and between the PFTs.

Forests are important components of global vegetation. They cover most non-arid land surfaces and can be characterized in terms of taxonomic differences and differences in leaf form and phenological habit. We focused on just three major forest types: evergreen needleleaf forest (ENF), evergreen broadleaf forest $(\mathrm{EBF})$ and deciduous broadleaf forest (DBF). We excluded deciduous needleleaf forest (DNF) 
because of its limited global distribution. These three forest types present a useful model system for examining whether trait variation can explain the biogeographical patterns of different adaptive strategies at global scale.

The objectives of this study were: (1) to quantify how much of the observed global biogeographical variation in area occupied by each forest PFT could be explained by adding trait variation into the CABLE model (i.e. compared to using single values for all plant trait parameters); and (2) to ask whether this bottom-up approach has higher explanatory power than that of an empirical, phenomenological model.

\section{METHODS}

\section{The CABLE model}

The version of CABLE used for this study (version 2.0) includes a global biogeochemical model (CASA-CNP) (Wang et al., 2010). Unlike the previous version, described by Wang et al. (2010), both canopy leaf area index and maximal leaf carboxylation rate $\left(v_{\mathrm{cmax}}\right)$ are prognostic variables that are predicted by the biogeochemical model. Canopy leaf area index is simulated as a function of leaf carbon pool size, while both leaf mass per area and $v_{\text {cmax }}$ are calculated as a function of leaf nitrogen using parameter values from Kattge et al. (2009). Further details can be found in Wang et al. (2012) and Zhang et al. (2013b).

This version of CABLE has previously been used to quantify the benefits of incorporating covariance in leaf trait parameters when estimating the uncertainty of annual gross primary productivity (GPP) in different PFTs (Wang et al., 2012), and for assessing the effects of nutrient limitation and land-use change on the terrestrial carbon cycle (Zhang et al., 2011, 2013b, 2014). Evaluations of model performance have shown that CABLE with CASA-CNP can reproduce quite well the global mean annual GPP (as estimated by Beer et al., 2010; Wang et al., 2012), global evapotranspiration (Zhang et al., 2013a) and mean annual runoff from the 13 largest catchments (Zhou et al., 2012), and major global biogeochemical fluxes and pool sizes of carbon, nitrogen and phosphorus (Wang et al., 2010).

\section{Dependence of NPP on key plant traits in CABLE}

Plant traits such as leaf $\mathrm{N}$ concentration and leaf area index (LAI) strongly influence ecosystem NPP (Reich, 2012). Based on our sensitivity analysis (see Appendix S1 in the Supporting Information), we identified the four most sensitive traits for simulating NPP by CABLE, for each of the three forest PFTs. They were: leaf life span $\left(\tau_{1}\right)$, fraction of NPP allocated to leaf $\left(a_{\mathrm{L}}\right)$, leaf $\mathrm{N}$ concentration $\left(N_{\mathrm{l}}\right)$ and basal respiration rate $\left(r_{\mathrm{r}}\right.$ for root; $r_{\mathrm{w}}$ for wood). Leaf respiration rate is assumed in CABLE to be proportional to maximal carboxylation rate, which is strongly correlated with leaf $\mathrm{N}$ concentration. Previous work showed that the more accurate parameterization of traits such as leaf N, fraction of NPP allocated to leaf and leaf life span in CABLE improved its ability to predict LAI and GPP across the boreal forest (Reich et al., 2014). NPP is calculated as the difference between stand-scale photosynthesis $\left(F_{\mathrm{gpp}}\right.$ in $\mathrm{gC} \mathrm{m}^{-2}$ day $\left.{ }^{-1}\right)$ and autotrophic respiration. Photosynthesis is a function of maximum

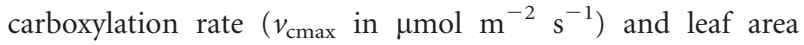
index $\left(L\right.$ in $\mathrm{m}^{2} \mathrm{~m}^{-2}$ ), and autotrophic respiration is a function of tissue nitrogen concentration and basal respiration rate. NPP (in $\mathrm{gC} \mathrm{m}^{-2} \mathrm{day}^{-1}$ ) as simulated in CABLE can be described using the following equation:

$\mathrm{NPP}=F_{\mathrm{gpp}}\left(L, v_{\mathrm{cmax}}\left(N_{\mathrm{l}}\right)\right)-R_{\mathrm{l}}-R_{\mathrm{w}}\left(N_{\mathrm{w}}, \frac{r_{\mathrm{w}}}{365}\right)-R_{\mathrm{r}}\left(N_{\mathrm{r}}, \frac{r_{\mathrm{r}}}{365}\right)-R_{\mathrm{g}}$

where $R_{\mathrm{l}}$ is leaf respiration rate in $\mathrm{gC} \mathrm{m}^{-2}$ day $^{-1}$, assumed to be proportional to leaf carboxylation rate (dependent on leaf $\mathrm{N}$ concentration and growth temperature), while $R_{\mathrm{w}}$ and $R_{\mathrm{r}}$ are wood respiration and root respiration rates in $\mathrm{gC} \mathrm{m}^{-2}$ day $^{-1}$, which are proportional to the amount of tissue nitrogen in wood and root, respectively. The basal respiration rate $r$ is the respiration rate per unit tissue nitrogen at the temperature of $10{ }^{\circ} \mathrm{C}$ in $\mathrm{gC}(\mathrm{gN})^{-1} \mathrm{~m}^{-2}$ year ${ }^{-1}$ (we use the same value for root $r_{\mathrm{r}}$ and wood $\left.r_{\mathrm{w}}\right)$ :

$R_{\mathrm{l}}=c v_{\mathrm{cmax}}\left(T_{1}, N_{\mathrm{l}}\right) \times\left(12 \times 10^{-6}\right) \times 24 \times 3600$

$R_{\mathrm{w}}=r_{\mathrm{w}} N_{\mathrm{w}} \exp \left[308.56\left(\frac{1}{56.02}-\frac{1}{T_{\mathrm{a}}+46.02}\right)\right] / 365$

$R_{\mathrm{r}}=r_{\mathrm{r}} N_{\mathrm{r}} \exp \left[308.56\left(\frac{1}{56.02}-\frac{1}{\bar{T}_{\mathrm{s}}+46.02}\right)\right] / 365$.

In equation (2) $c$ is a dimensionless empirical coefficient equal to 0.015 for C3 plants (Sellers et al., 1996), and $v_{\text {cmax }}$ (maximum leaf carboxylation rate) is a function of leaf temperature $\left(T_{\mathrm{l}}\right)$ and leaf nitrogen amount $\left(N_{\mathrm{l}}\right.$; units $\left.\mathrm{gN} \mathrm{m}^{-2}\right)$ (Kattge et al., 2009). $r_{\mathrm{w}}$ and $r_{\mathrm{r}}$ are the wood and root maintenance respiration rates at a mean daily air temperature $\left(T_{\mathrm{a}}\right)$ of $10{ }^{\circ} \mathrm{C}$, and mean daily soil temperature of the rooting zone $\left(\bar{T}_{\mathrm{s}}\right)$ of $10{ }^{\circ} \mathrm{C}$, respectively. $N_{\mathrm{w}}$ and $N_{\mathrm{r}}$ are the amounts of nitrogen in wood and root tissue, respectively, in $\mathrm{gN} \mathrm{m}^{-2}$. The temperature dependence in equations (3) and (4) is based on Lloyd \& Taylor (1994). $R_{\mathrm{g}}$ is growth respiration rate in $\mathrm{gC} \mathrm{m}^{-2}$ day $^{-1}$ and is a function of the leaf $\mathrm{N}: \mathrm{P}$ ratio:

$R_{\mathrm{g}}=\left(1-y_{\mathrm{g}}\right)\left(F_{\mathrm{gpp}}-R_{\mathrm{l}}-R_{\mathrm{w}}-R_{\mathrm{r}}\right)$

and

$y_{\mathrm{g}}=0.65+0.2 \frac{p_{\mathrm{n}}}{p_{\mathrm{n}}+1 / 15}$

where $p_{\mathrm{n}}$ is the P:N ratio of leaf tissue ( $\left.\mathrm{gP} / \mathrm{gN}\right)$. Equation (6) is based on work by Kerkhoff et al. (2005), who showed that plant growth efficiency $\left(y_{\mathrm{g}}\right)$ increases with leaf $\mathrm{P}: \mathrm{N}$ ratio.

The leaf area index in CABLE is calculated as the product of leaf carbon $\left(C_{\mathrm{l}}\right)$ and specific leaf area (SLA, in $\mathrm{m}^{2}(\mathrm{gC})^{-1}$; denoted by $\sigma)$. That is 
$L=C_{1}\left(a_{\mathrm{L}}, \tau_{1}\right) \sigma$

where $C_{\mathrm{l}}$ is the size of the leaf carbon pool in $\mathrm{gC} \mathrm{m}^{-2}$, which depends on two particularly sensitive traits: $a_{\mathrm{L}}$ (unitless) and $\tau_{1}$ (in years). The equation governing $C_{1}$ dynamics in CABLE is given by

$\frac{\mathrm{d} C_{\mathrm{l}}}{\mathrm{d} t}=\mathrm{NPP} a_{\mathrm{L}}-\frac{\tau_{1}^{-1} C_{\mathrm{l}}}{365}$.

More details about the dependence of $F_{\text {gpp }}$ on leaf nitrogen as used in CABLE can be found in Wang et al. (2012).

Variation in plant traits has been considered in some modelling studies (Scheiter \& Higgins, 2009; Wang et al., 2012; Scheiter et al., 2013; Fyllas et al., 2014; Reich et al., 2014; van Bodegom et al., 2014; Sakschewski et al., 2015). However, it is still unknown whether including this variation in global land models will improve our prediction of the global biogeography of different PFTs, particularly at the global scale. Fisher et al. (2015) used an ensemble simulation approach to assess the effect of parameter variation on the simulated area fractions of evergreen and deciduous trees, but they did not extend their study to the global scale or to the co-dominance of different plant strategies in their study regions. Here we incorporated the observed means, variances and covariances of the four most important traits into CABLE, using 200 simulations. Each simulation used one set of the randomly resampled values of these four trait parameters for each PFT. We assumed that the log-transformed parameter values were normally distributed. Means, variances and covariances were obtained from the GLOPNET database (Wright et al., 2004), which has recently been updated with a substantial number of additional observations by P. B. Reich, J. Oleksyn and I. Wright I. (pers. comm.) - statistics of these data have been summarized in Appendix S2. Hereafter these simulations are called ensemble simulations.

As well as differing in their trait values, the various forest PFTs used in CABLE differ in phenology - the evergreen and deciduous habits represent two very different carbon investment strategies. Growing season length for deciduous forests in CABLE is defined as running from the onset of leaf emergence to the end of leaf senescence, both of which are prescribed and vary with the latitude of the location, based on remotely sensed observations (Zhang et al., 2004, 2005). Most of the NPP will be allocated to leaves during a model prescribing a period of rapid leaf growth from the onset of leaf emergence, while no NPP will be allocated to leaves during the period of leaf senescence. Details can be found in Appendix S4. The rate of increase in canopy LAI for evergreen forests depends on the seasonal cycle of NPP, on the proportion of NPP allocated to leaves, on SLA and on leaf age, which is considered as leaf turnover rate in the model.

\section{Estimates of the global land-cover fraction of different forest types from a remote sensing product}

Land-area cover fraction here is defined as the area fraction of a land cell covered by a particular forest functional type.
We calculated the land-area cover fraction for each of the three forest PFTs in each land cell (at a spatial resolution of $\left.0.5^{\circ} \times 0.5^{\circ}\right)$ from satellite data - specifically, using data from the International Satellite Land Surface Climatology Project (ISLSCP) data initiative II: vegetation continuous field (VCF) (DeFries \& Hansen, 2009).

The ISLSCP II dataset $\left(0.5^{\circ} \times 0.5^{\circ}\right.$ spatial resolution; time period 1992-93) provides land-area cover fractions of different plant life-forms (tree versus herbaceous; and also bare land) or phenology (evergreen or deciduous) or leaf morphology (needleleaf or broadleaf). In this study we only included land area where the total tree cover fraction was larger than $50 \%$ (Fig. S3). The total forest area represents the tree (woody vegetation with tree height $>5 \mathrm{~m}$ ) fraction. We estimated the land-area cover fractions of the three forest PFTs in each land cell based on the following known information from the dataset: land-area cover fraction of evergreens $\left(A_{\mathrm{E}}\right)$, deciduous forest $\left(A_{\mathrm{D}}\right)$, broadleaf forest $\left(A_{\mathrm{B}}\right)$ and needleleaf forest $\left(A_{\mathrm{N}}\right)$. With the knowledge that DNF are restricted to the central eastern Russia region (latitude $>45{ }^{\circ} \mathrm{N}$ and longitude $>75{ }^{\circ} \mathrm{E}$ ), where the land-area cover fraction of EBF is negligible, we were able to solve the following equations in each land cell for the four unknowns [land-area cover fraction of ENF $\left(A_{\mathrm{EN}}\right), \operatorname{EBF}\left(A_{\mathrm{EB}}\right), \mathrm{DNF}$ $\left(A_{\mathrm{DN}}\right)$ and $\mathrm{DBF}\left(A_{\mathrm{DB}}\right)$; Fig. S4]:

$$
\left.\begin{array}{r}
A_{\mathrm{EB}}=0 \\
A_{\mathrm{EB}}+A_{\mathrm{DB}}=A_{\mathrm{B}} \\
A_{\mathrm{EB}}+A_{\mathrm{EN}}=A_{\mathrm{E}} \\
A_{\mathrm{DB}}+A_{\mathrm{DN}}=A_{\mathrm{D}}
\end{array}\right\} \text { at lat. }>45^{\circ} \mathrm{N} \text { and long. }>75^{\circ} \mathrm{E}
$$

\section{Estimates of global land-area cover fractions of different forest PFTs from ensemble simulations using CABLE}

To estimate the land-area cover fraction for each PFT in each forested land cell, we first assumed that all three woody PFTs can potentially grow in all forested areas (Fig. S3). Annual NPP was thus calculated for each of the three PFTs in every forested land cell. To account for the variance of the four important traits for each PFT we used ensemble CABLE simulations with 200 members.

In each forested land cell we calculated the number of winning samples from each PFT by comparing all possible $\left(200^{3}\right)$ combinations of the NPP estimates with the winning PFT samples having the greatest NPP. The land-area cover fraction of one PFT in a land cell was estimated as the abundance of winning PFT samples multiplied by the fraction of the total forested area from remote sensing data (DeFries \& 
Table 1 Configurations of the three different simulations used for estimating area fractions of different forest plant functional types (PFTs)

\begin{tabular}{lllll}
\hline Simulation & $\begin{array}{l}\text { Uses NPP } \\
\text { as a proxy }\end{array}$ & $\begin{array}{l}\text { CABLE } \\
\text { simulation }\end{array}$ & $\begin{array}{l}\text { No. of } \\
\text { simulations }\end{array}$ & $\begin{array}{l}\text { Variation } \\
\text { of traits }\end{array}$ \\
\hline S1 & Yes & Yes & $200 \times 3$ & Yes \\
S2 & Yes & Yes & $1 \times 3$ & No \\
PM & No & No & 1 & No \\
\hline
\end{tabular}

Simulation scenarios 1 (S1) and 2 (S2) use the Australian Community Atmosphere-Biosphere-Land Exchange model (CABLE); the phenomenological model (PM) uses an empirical model that relates area fraction of a forest PFT to mean annual surface air temperature based on the Princeton Global Forcing dataset (Sheffield et al., 2006).

Hansen, 2009). The abundance of the winning PFT samples was calculated as the fraction of the number of winning PFT samples in all $200^{3}$ NPP combinations.

We chose to present results from 200 ensemble simulations because we found that further increases in ensemble size did not significantly change the estimated land-area cover fraction for all three forest PFTs.

\section{Different simulation approaches for estimating land- area fractions of different forest PFTs}

In biogeographical studies, environmental conditions are assumed to be primary constraints on species distributions. We designed three experiments (Table 1) to evaluate the significance of leaf trait variation, and the difference between process-based modelling and empirical modelling, when simulating the global biogeography of different PFTs. The first experiment (S1) used ensemble simulations in CABLE, as described above. The second experiment (S2) was designed for assessing how well we could estimate the area fractions of different forest PFTs when assigning mean trait differences between PFTs, but without considering intra-PFT variation as well. That is, only the trait means were used when calculating NPP of each PFT in each grid cell, and trait variance/ covariance was ignored. Otherwise, the land-area cover fractions were calculated as in experiment S1. The third experiment compared simulation results with those from a phenomenological model (PM) which predicted the area fractions of different forest PFTs based on statistical relationships derived from ISLSCP II data (DeFries \& Hansen, 2009) in combination with data for mean annual air temperature (from the Princeton Global Forcing dataset) (Sheffield et al., 2006). Analysis of the correlation between land-area fractions and different climatic variables, such as air temperature and precipitation, found that mean annual air temperature was the climatic variable with the strongest correlation. Further details of the phenomenological model are provided in Appendix S5.

\section{Statistical assessment of CABLE estimates}

Normalized mean error (NME) (Kelley et al., 2012) and the squared correlation coefficient $\left(R^{2}\right)$ were used to assess the agreement between the model estimates of land-area cover fractions and remote sensing data estimates (ISLSCP) for each PFT, globally. NME and $R^{2}$ are defined as:

$\mathrm{NME}_{i}=\frac{\sum_{j=1}^{n}\left|f_{i, j}^{\mathrm{m}}-f_{i, j}^{\mathrm{o}}\right|}{\sum_{j=1}^{n}\left|f_{i, j}^{\mathrm{o}}-\bar{f}_{i}^{\mathrm{o}}\right|}$

$R_{i}^{2}=\left(\frac{n^{-1} \sum_{j=1}^{n}\left(f_{i, j}^{\mathrm{m}}-\bar{f}_{i}^{\mathrm{m}}\right)\left(f_{i, j}^{\mathrm{o}}-\bar{f}_{i}^{\mathrm{o}}\right)}{\sigma_{i}^{\mathrm{m}} \sigma_{i}^{\mathrm{o}}}\right)^{2}$

where $f_{i, j}^{\mathrm{m}}$ is the land-area cover fraction as estimated from the CABLE ensemble simulations for land cell $j$ and forest PFT $i$, and the corresponding value from the ISLSCP II dataset is $f_{i, j}^{\mathrm{o}} ; \bar{f}_{i}^{\mathrm{m}}, \sigma_{i}^{\mathrm{m}}, \bar{f}_{i}^{\mathrm{o}}$ and $\sigma_{i}^{\mathrm{o}}$ are the mean and standard deviation of $f_{i, j}^{\mathrm{m}}$ and $f_{i, j}^{\mathrm{o}}$ over all forested land cells, respectively, for PFT $i ; n$ is total number of forested land cells globally at $1^{\circ} \times 1^{\circ}$ spatial resolution.

NME measures an overall normalized spatial error of the model whilst $R^{2}$ provides spatial correlation between two different estimates. It is possible for two spatial patterns to be perfectly correlated with systematic biases. To avoid this problem of using $R^{2}$ alone, a measure using both NME and $R^{2}$ is necessary (Taylor, 2001). Perfect agreement between the two estimates of land-area cover fractions for a PFT would have $\mathrm{NME}=0, R^{2}=1$.

\section{RESULTS}

\section{Comparison of modelled land-area cover fractions with remotely sensed data}

Experiment $\mathrm{S} 1$ predicted ENF as being generally found between latitudes $40{ }^{\circ} \mathrm{N}$ and $70{ }^{\circ} \mathrm{N}$ with land-area cover fractions of up to 0.6 (Fig. 1a), and EBF within tropical region $\left(15^{\circ} \mathrm{N}\right.$ to $\left.25^{\circ} \mathrm{S}\right)$ is generally with a land-area cover

Table 2 Values of two different metrics for evaluating the agreement between estimated area fractions using three different simulations (scenario 1, S1; scenario 2, S2; phenomenological model, PM) and observed data from the International Satellite Land Surface Climatology Project data initiative II (ISLSCP).

\begin{tabular}{|c|c|c|c|c|c|c|}
\hline \multirow[b]{2}{*}{ Simulation } & \multicolumn{3}{|l|}{$\mathrm{R} 2$} & \multicolumn{3}{|l|}{ NME } \\
\hline & ENF & $\mathrm{EBF}$ & $\mathrm{DBF}$ & ENF & $\mathrm{EBF}$ & DBF \\
\hline S1 & 0.802 & 0.868 & 0.129 & 0.340 & 0.286 & 1.073 \\
\hline S2 & 0.574 & 0.719 & 0.00014 & 0.633 & 0.473 & 1.745 \\
\hline PM & 0.696 & 0.722 & 0.022 & 0.42 & 0.48 & 1.104 \\
\hline
\end{tabular}

$R^{2}$ is the square of linear correlation and NME is normalized mean error. ENF, EBF and DBF represent evergreen needleleaf forest, evergreen broadleaf forest and deciduous broadleaf forest, respectively. 
(a)

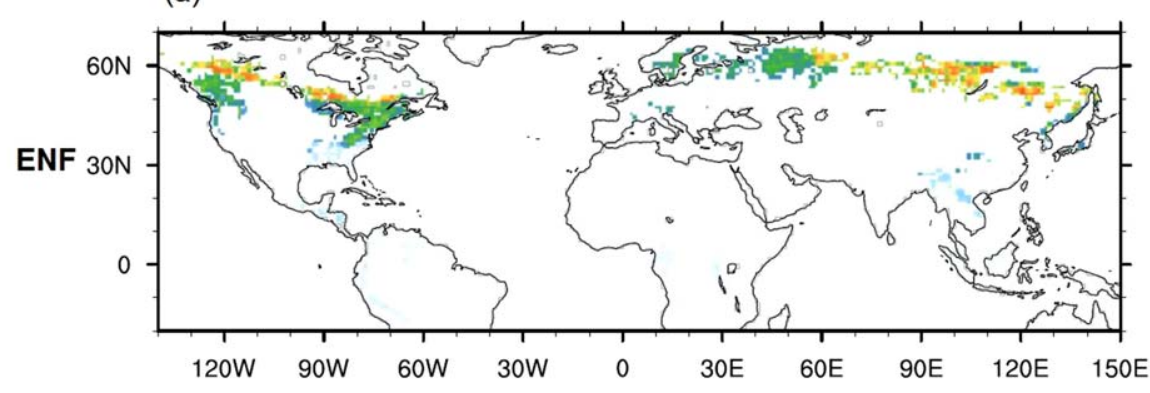

(c)

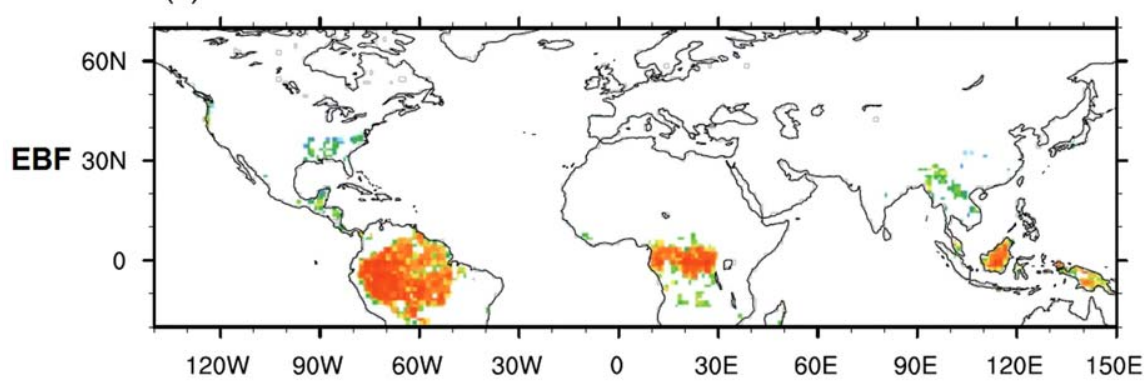

(e)

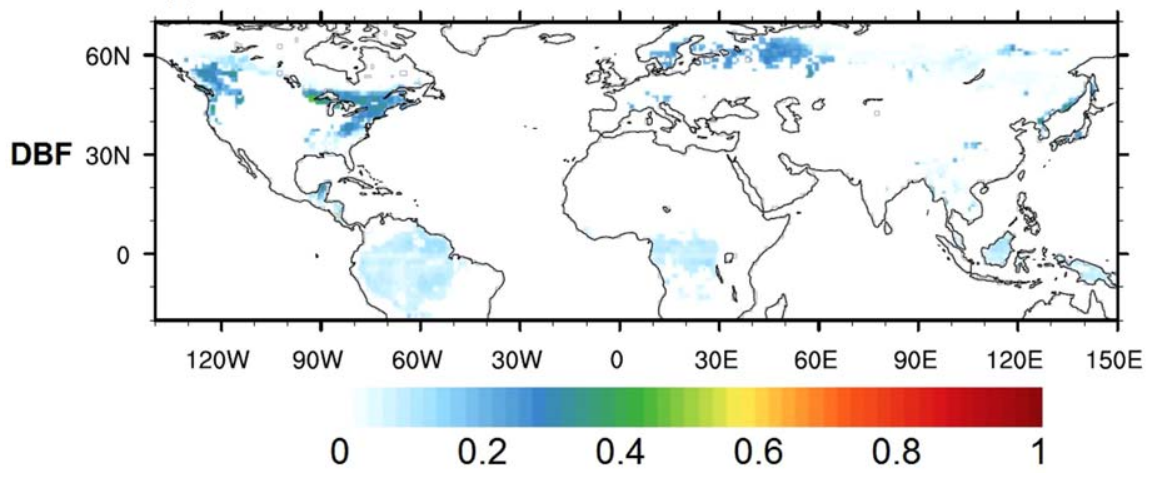

(b)

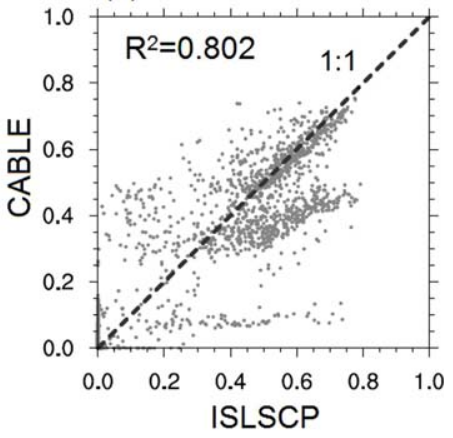

(d)

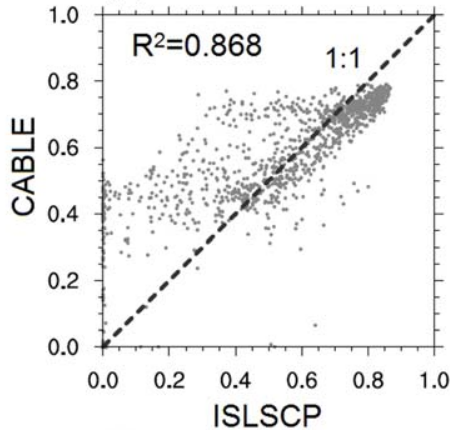

(f)

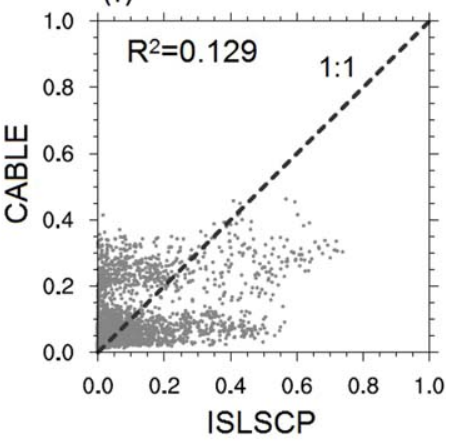

Figure 1 Estimates of land-area cover fractions from the Australian Community Atmosphere-Biosphere-Land Exchange (CABLE) model ensemble simulations for (a) evergreen needleleaf forest (ENF), (c) evergreen broadleaf forest (EBF), and (e) deciduous broadleaf forest (DBF). Panels (b), (d) and (f) show comparisons of the land-area fractions from CABLE simulations and those from the International Satellite Land Surface Climatology Project data initiative II (ISLSCP) (DeFries \& Hansen, 2009).

fraction $>0.6$, except in parts of southern Asia and the south-eastern USA (Fig. 1c). For ENF and EBF the results of experiment S1 were highly correlated with the ISLSCPderived estimates (Fig. 1b \& d), and captured the latitudinal patterns well (i.e. that ENFs dominate in high-latitude regions, and EBFs dominate in tropical regions; Figs 1a-d \& S4). Experiment S1 also predicted that DBFs were predominantly distributed in northern mid to high latitudes (Fig. 1e). Major areas of DBF (where the land-area fraction of DBF is $>0.3$ ) were predicted in the eastern USA, western Canada and northern Europe, and area fractions of DBF were generally small in the tropics, where the DBF land-area fraction is $<0.2$. Although the general pattern is captured, discrepancies are still large in the above regions compared with ISLSCP estimates, As a result, the correlation of DBFs from simulation S1 and the ISLCP estimates was weak. Overall DBFs co-dominate with ENF or EBF in most regions globally. However, predicted land-area fractions of DBF were not highly correlated with ISLSCP-derived estimates compared with ENF and EBF (Fig. 1f).

\section{Annual NPP - a proxy for plant growth rate}

In this study we used annual NPP as a proxy for plant growth rate. If this approximation is reasonably accurate, the mean NPP of a PFT in its observed dominant regions should be higher than those of other PFTs. To assess the reliability of this proxy, we calculated the mean NPP of each PFT in its dominant regions using the simulated annual NPP for that PFT from experiment $\mathrm{S} 1$. 


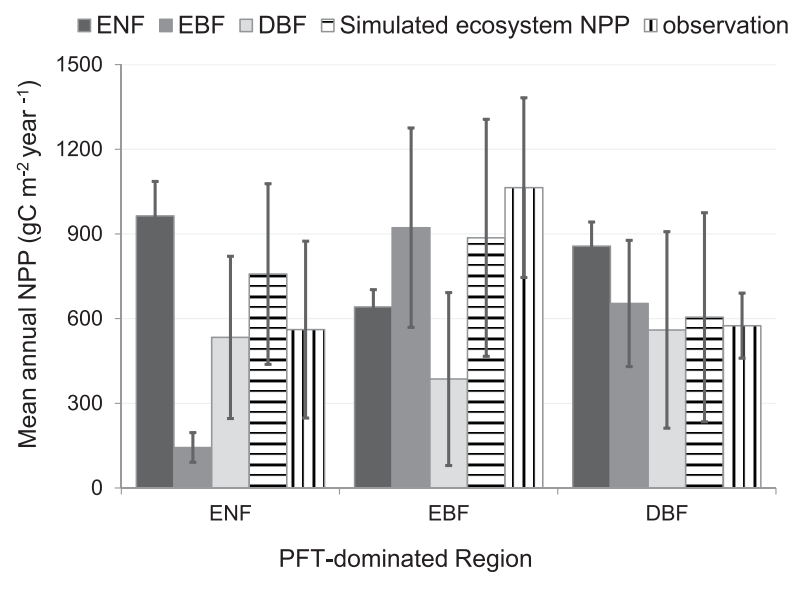

Figure 2 Mean and standard deviation of annual net primary productivity (NPP) in three forest-dominated regions: evergreen needleleaf forest (ENF), evergreen broadleaf forest (EBF) and deciduous broadleaf forest (DBF). The dominant regions of a plant functional type (PFT) were identified as those areas where the fraction of that PFT was more than $50 \%$ based on continuous fields of vegetation cover fraction data from ISLSCP data (DeFries \& Hansen, 2009). For each region we show the mean and standard deviation of ensemble-simulated or observed annual NPP from scenario 1 (S1), with five groups: (1) ENF in black; (2) EBF in dark grey; (3) DBF in light grey; (4) simulated ecosystem NPP in horizontal hatch (calculated from the NPP average over three PFTs and weighted by the estimated PFT land-area cover fractions); and (5) observations in vertical hatch. Error bars represents one standard deviation from ensemble samples.

Figure 2 compares the mean and standard deviation of the simulated NPP from experiment S1 for different PFTs. It shows that in regions in which they are dominant ENF and EBF have substantially greater mean NPP than other PFTs in those regions. Therefore, using NPP as a proxy for plant growth rate appears capable of explaining why evergreens dominate in evergreen-dominated regions. However, the mean NPP of DBF in the deciduous-dominated regions was the lowest and most variable of the different PFTs in the DBF-dominated regions. The reason for this will be further discussed.

The simulated mean annual NPP at the ecosystem scale, or the simulated ecosystem NPP, was calculated from the NPP averaged over the three PFTs and weighted by the estimated PFT land-area cover fractions from simulation S1. The simulated ecosystem NPPs were compared with the mean of the observed NPP from Michaletz et al. (2014) in each PFTdominated region (Fig. 2). The simulated ecosystem NPP in each of three different forest-dominated regions was within one standard deviation of the mean of the observations. Even though the simulated ecosystem NPP was substantially greater than that observed in ENF-dominated regions, or lower than observed in EBF-dominated regions, experiment S1 did successfully capture the global pattern for higher NPP in EBF-dominated tropical regions than in ENF-dominated boreal regions.

\section{Effects of plant traits and their variation within PFTs on simulated land-area fractions}

Next we compared the simulated land-area cover fractions of each forest PFT with data from ISLSCP. We used $R^{2}$ and NME to assess the performance of three different approaches (S1, S2 and PM; see Table 1). S1 used 200 ensemble simulations to account for the variation and covariation of the four key plant traits; S2 used only a single value for each of the four key plant traits for each PFT. The PM approach estimated the land-area fractions of a forest PFT using a linear relationship between mean annual surface air temperature and the estimated land-area cover fractions from the ISLSCP data product.

S1 showed the best performance among the three approaches, based on its values of $R^{2}$ (highest) and NME (lowest). In particular, compared with S2, the performance of S1 improved substantially when variation and covariation of the key plant traits was taken into account for all three PFTs: $R^{2}$ increased from 0.000 (S2) to 0.129 (S1) and NME decreased from 1.745 (S2) to 1.073 (S1).

\section{Variation of the estimated land-area fraction of a PFT with mean annual surface air temperature}

We also illustrated how land-area fractions of different forest PFTs varied with mean annual air temperature $\left(T_{\mathrm{a}}\right)$. Results from the three approaches were compared with the ISLSCP remote sensing data (DeFries \& Hansen, 2009). ISLSCP data showed a strong dominance of ENF in cold regions with $T_{\mathrm{a}}<0{ }^{\circ} \mathrm{C}$ and of EBF in warm regions with $T_{\mathrm{a}}>20{ }^{\circ} \mathrm{C}$. As a result, the dominance of evergreen types was weakest and the dominance of DBF was strongest at a $T_{\mathrm{a}}$ about $15{ }^{\circ} \mathrm{C}$ (see Fig. 3). This pattern for evergreen versus deciduous forest types was quite well captured by $\mathrm{S} 1$, but very poorly by $\mathrm{S} 2$ (Fig. 3d).

Experiment S2 (using fixed plant trait values) also simulated well the dominance of EBF in warm regions and ENF in cold regions, but significantly overestimated the area fractions of both evergreen forest types and underestimated the land-area fraction of DBF, particularly in those regions with $T_{\mathrm{a}}$ between $5{ }^{\circ} \mathrm{C}$ and $20{ }^{\circ} \mathrm{C}$ (Fig. $3 \mathrm{~d}$ ). These results suggest that unless the variation and covariation of key plant traits are accounted for, co-dominance between DBF and ENF or $\mathrm{EBF}$ in the most temperate and subtropical regions will be significantly underestimated.

\section{Bias in the estimated land-area cover fractions of different PFTs}

In general, among the three different approaches, the estimated land-area fractions using S1 agreed best with those from ISLSCP data. However, comparisons in Fig. 3 also showed that the estimated land-area cover fractions using S1 were higher for EBF, and slightly lower for ENF, than those estimates from ISLSCP data at $T_{\mathrm{a}}$ between $0{ }^{\circ} \mathrm{C}$ and $24{ }^{\circ} \mathrm{C}$ (see Fig. 3a, b). Here we further address these differences. 
Figure 3 (a)-(c) Variation in mean land-area cover fractions for each PFT in relation to mean annual surface air temperature (MAT). The grey solid line represents scenario $1(\mathrm{~S} 1)$, the grey dotted line represents scenario 2 (S2) and the grey dashed line represents the

phenomenological model (PM). Observed data from ISLSCP are shown with a solid black line. Panel (d) shows data for evergreen forest types (evergreen needleleaf, ENF, and evergreen broadleaf, EBF) combined.
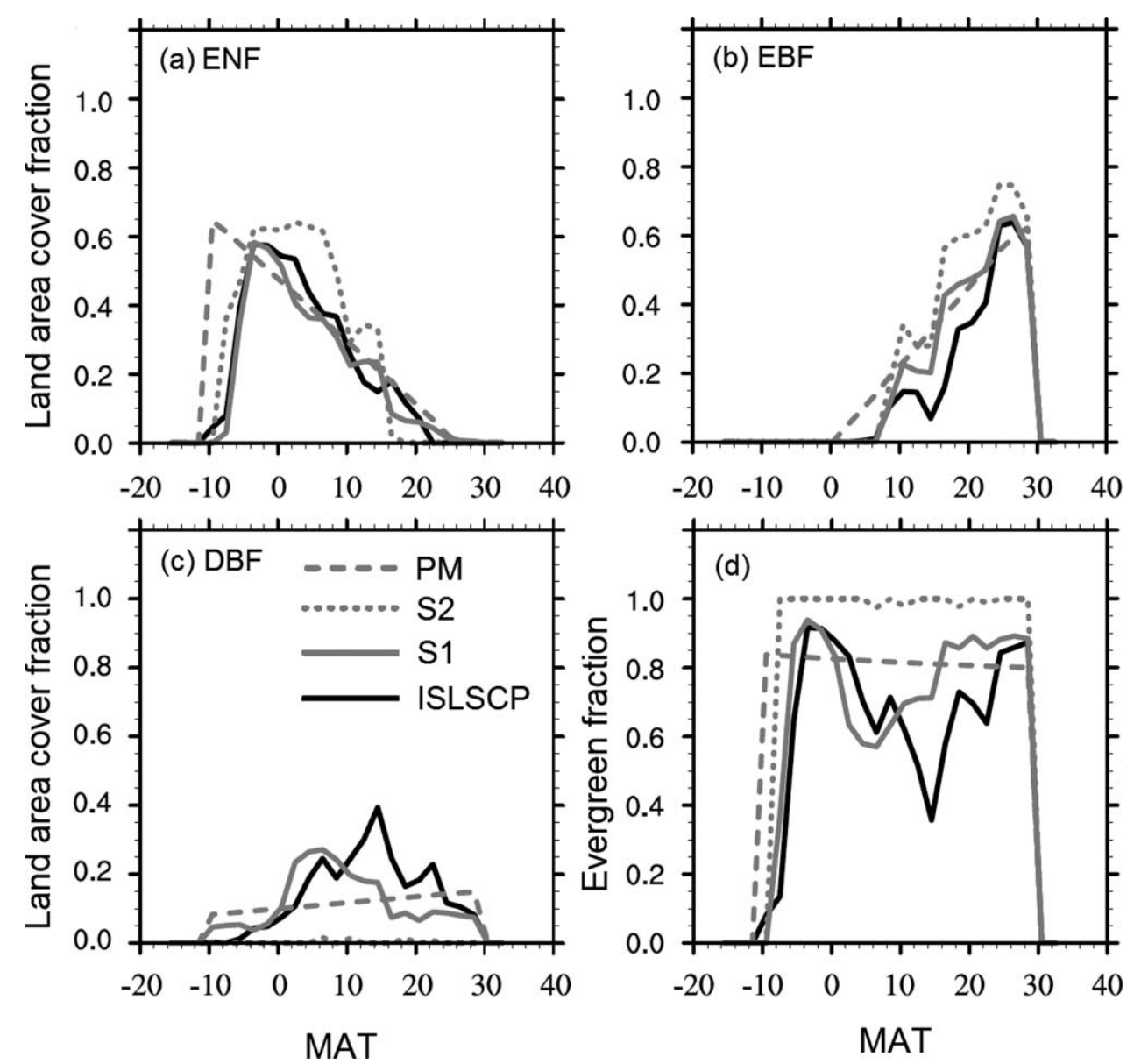

As shown in Fig. 4, the absolute differences in the estimated land-area cover fractions between S1 and ISLSCP data were generally $<20 \%$ in most forested regions. In western and northern Europe, our CABLE simulations (S1) underestimated the land-area fraction of ENF by more than $15 \%$, and overestimated the land-area fraction of DBF by a similar amount. In eastern Russian and the eastern USA, S1 overestimated the land-area fraction of ENF by more than $10 \%$ and underestimated that of DBF by a similar amount. In the southern USA, southern Amazon, southern China and central Africa, S1 overestimated the land-area fraction of EBF by more than $10 \%$ and underestimated that of DBF by a similar amount and also underestimated the land-area fraction of EBF by more than $5 \%$ in central Amazon and overestimated that of DBF by a similar amount in the same region (see Fig. 4).

\section{DISCUSSION}

This study demonstrated the success of simulating the bimodal (boreal and tropical) biogeographical distribution of evergreen forests by incorporating functional trait data into a bottom-up approach (see Fig. 3d). In a previous study, Kikuzawa (1991) showed how leaf life span seemingly varies under different climatic conditions to maximize net carbon gain per unit leaf mass over a leaf's lifetime. His theory successfully predicted the bi-modal latitudinal distribution of evergreen forests, but was not applied globally. As Givnish (2002) argued, possible weaknesses of Kikuzawa's study were that it did not extend to consideration of other key traits that influence plant growth rate (specifically, leaf mass per unit area and leaf nitrogen concentration) and did not assess the relative advantage of different strategies. This paper, using information on four traits from a global plant trait database and a process-based land surface model, is to our knowledge the first to estimate the biogeographical variation in forest functional types at global scale.

One approach used by plant ecologists for predicting the biogeographical distributions of different PFTs is to study empirical relationships between species distributions and climate (Araujo \& Peterson, 2012). Information on climatic limits from such studies has been used extensively in DGVMs. Our analyses showed that our approach (which could be termed a 'trait continua-based modelling approach') predicted global biogeographical variation of different forest types slightly better than a purely empirical (phenomenological) approach based on mean annual surface temperature. This suggests that a trait continua-based approach could also provide information on vegetation climatic limits as good as that supplied by the previous empirical method.

Our study also showed that global biogeographical patterns of major forest types can be simulated using just a few 


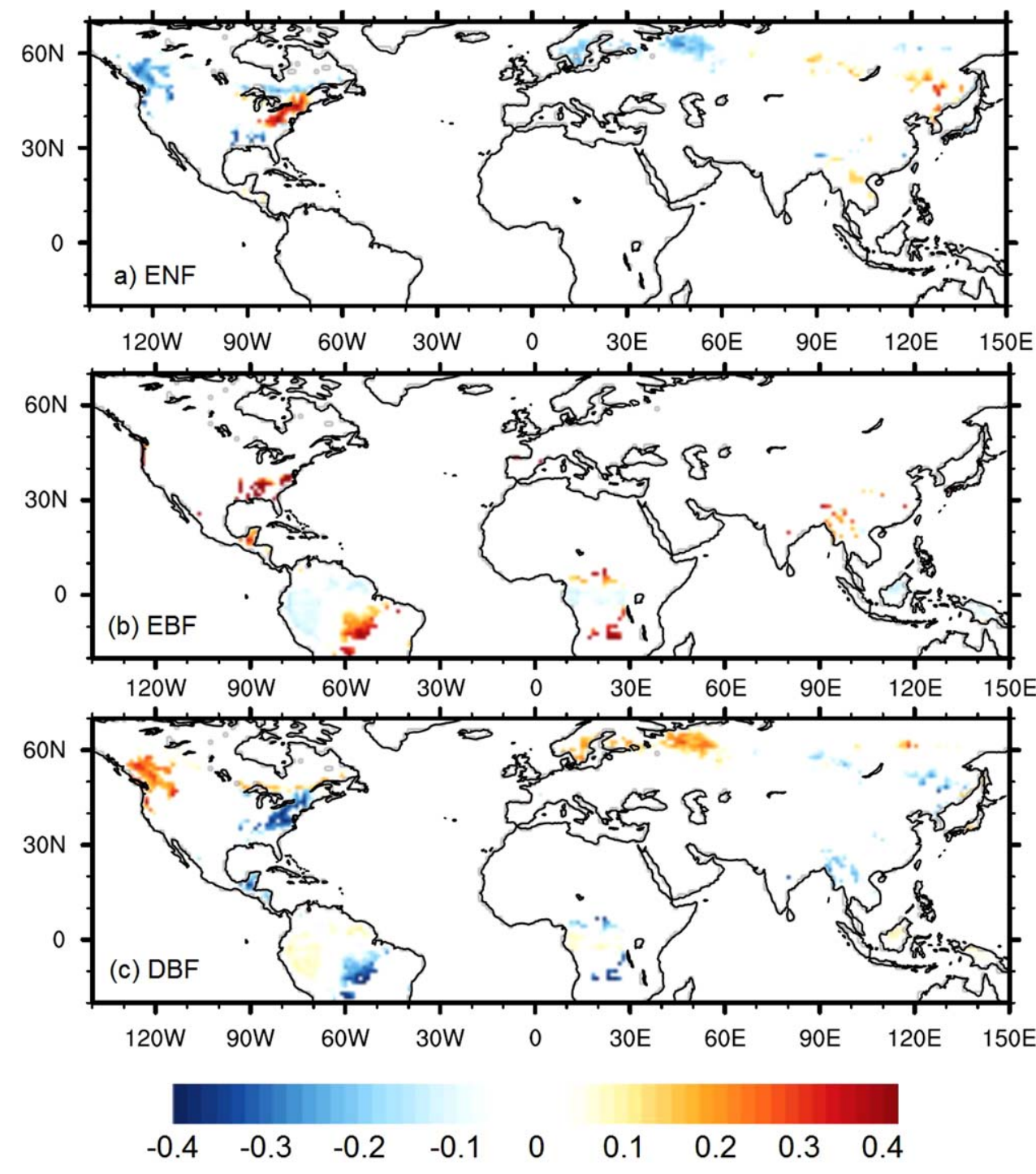

Figure 4 Differences in landarea cover fractions between the estimates from scenario 1 (S1) and ISLSCP data for (a) evergreen needleleaf forest (ENF), (b) evergreen broadleaf forest (EBF), and (c) deciduous broadleaf forest (DBF). Positive values represent overestimation of S1. key functional traits (and using trait variance-covariance data, not just means). We argue that this approach shows great promise, especially as global trait databases have become increasingly comprehensive in terms of species coverage and the number of traits included (Wright et al., 2004; Kattge et al., 2011). Recent trait-based studies have also found that trait variances as well as means (within functional groups) should be considered in modelling practice in order to represent the diversity of ecosystem functions (Norberg et al., 2001; Wang et al., 2012; Enquist et al., 2015). We demonstrated the utility of ensemble simulation approaches for simulating the co-dominance of multiple PFTs. This issue was recently explored by Fisher et al. (2015) using a relatively small ensemble size $(n=15)$ at a regional scale. With everincreasing computing power, ensemble simulations should become a very useful tool for studying plant competition.

Moreover, there are several questions worth exploring further. First, is the PFT growth rate a good proxy for quantifying competitiveness? The occurrence of species under a given environment is presumably related to their fitness or competitiveness. Similar to a number of previous studies (Chabot \& Hicks, 1982; Kikuzawa, 1991; Norberg et al., 2001; Givnish, 2002; McMurtrie \& Dewar, 2011; Falster et al., 2012; Enquist et al., 2015), we used mean annual NPP as a proxy for growth rate and assume that the PFT with the maximum growth rate is more competitive. This assumption was supported by our model estimates of higher NPP of ENF and $\mathrm{EBF}$ in the regions were they are indeed observed to be dominant (Fig. 2). However, our results suggested that the NPP of DBF was not the highest in DBF-dominated regions. The results from the modelling of land-area cover fraction are the most biased to DBF. The main contribution to this bias compared with the ISLSCP database is from eastern US and South American tropical forest. This modelled bias could be attributed to two possible sources. First, the ISLSCP database could contain large uncertainties, especially in ecotones where multiple plant types coexist. Indeed, in the eastern US and South American tropical forest, deciduous forest, shrub land and grassland coexist and the ISLSCP estimations could overestimate deciduous forest by counting other plant type 
as deciduous forest. The second error could arise from bias of our model due to phenology, such as leaf area index and growing season length. Our model could underestimate these two phenological characteristics and therefore underestimate NPP.

Second, what can we learn from the higher NPP of one forest functional type over another? Previous studies have discussed the adaptive strategies of plants under different environmental conditions (Pianka, 1970; Grime, 1977; Reich et al., 1997; Wright et al., 2004; Grime \& Pierce, 2012). Plant adaptive strategies involve trade-offs among rates of resource capture, maintenance cost of tissues and reproductive capacity in a given environment (Grime \& Pierce, 2012). Different strategies can be indexed by different combinations of relevant plant traits, such as leaf C:N ratio, SLA, leaf life span, plant height and seed mass (Westoby et al., 2002). In this study, we focused on traits relevant to trade-offs between resource capture capacities and construction/maintenance costs. We incorporated traits into different functional groups in order to illustrate the advantages and disadvantages of different carbon investment strategies, which are measured via plant growth rate, i.e. NPP.

Future development of global land models will ideally include better representation of the processes leading to differential costs and benefits of different adaptive strategies under different climate conditions. Most global land models developed so far do not represent the costs of different plant functions, such as the carbon cost of nutrient uptake and water transport in plants. They only empirically simulate the responses of different plant types to cold temperature and water stress. Therefore they may not give a good explanation for some key functional differences between different PFTs under different climate conditions. Global models should also be further developed to improve their representation of some missing or poorly represented ecosystem processes, such as phenological processes, and cold stress parameterization.

Third, at the moment we are unable to determine the mechanism behind the co-dominance of different forest functional types. Plant growth rate (represented by NPP in this study) determines co-dominance of different forest functional types in our study. We found that DBF was distributed much more broadly than the other two forest types because variation of DBF plant traits led to greater variance in predicted NPP than for the other two forest types. It is also possible, and perhaps likely, that heterogeneity within any grid cell represented in our modelling is sufficiently large that conditions more conducive to different PFTs occur in different locations. Such heterogeneity is beyond the scope of the model as currently implemented.

The biogeographical pattern of PFTs is well captured by the trait continua-based modelling approach, S1. However, several issues have not been well addressed in this study. For example, anthropogenic effects of plantations and wood harvest may substantially increase or reduce forest PFT area cover fractions, and this is not accounted for in this study because CABLE does not yet simulate land-use change.

As in some other process-based modelling approaches, biases in the NPP simulated by global land models are usually inevitable. For example, the land-area cover fractions of DBF were poorly simulated in cold and warm biomes, possibly as a result of the overestimation of NPP in the cold regions and underestimation of NPP in the warm and tropical regions for DBF. The large overestimation of the landarea cover fraction of $\mathrm{DBF}$ at high latitudes may result from errors in the modelled response to cold stress in CABLE. Cold temperature in cold regions, and drought stress associated with warm temperatures in warm regions can affect leaf phenology, canopy carbon production and plant growth (Allen \& Ort, 2001; Heide, 2003). CABLE uses prescribed leaf phenology, which may have quite large uncertainties for DBF in those cold regions where there are very few observations (Zhang et al., 2006) as well as in modestly dry tropical forest area where deciduousness and its phenology can vary considerably both spatially and temporally. The leaf phenology used in this study for DBF was estimated as the mean of multipleyear observations from remote sensing measurements with 16-day temporal resolution. Drought stress can vary significantly over space and time, and those variations may not be accurately detected by remote sensing or be smoothed out when the estimates of leaf phenology at $10 \mathrm{~km} \times 10 \mathrm{~km}$ spatial resolution from remote sensing were averaged for use in CABLE at a spatial resolution of $0.5^{\circ} \times 0.5^{\circ}$ globally. This needs further investigation.

On the other hand, using the prescribed observationalbased leaf phenology has some advantage over a prognostic leaf phenology model because of the large errors in most current leaf phenology models (Richardson et al., 2012), i.e. those large errors may overwhelm the effect of the variation of the key plant traits in the CABLE-simulated NPP if one of the published prognostic global leaf phenology models were used. In CABLE, the key differences between evergreen and deciduous forest types are leaf life span (being $<1$ year for deciduous and $>1$ year for evergreen) and carbon allocation (being variable for deciduous and constant for evergreen). Therefore some of the influence of leaf phenology on the simulated NPP in CABLE has been accounted for by using the different values of leaf life span and allocation coefficients among different forest PFTs in CABLE. Other effects of leaf phenology on the simulated NPP, and therefore the estimated area fractions of different forest PFTs, such as length of the growing season, leaf C:N ratio and base respiration of roots are not accounted for in this study. As such effects of leaf phenology are likely to be considerable this needs further work in the future.

CABLE does not represent the distribution of different plant sizes within a PFT. Therefore CABLE does not account for the nonlinear relationship between plant size and NPP allocation representing allometric growth (Enquist \& Niklas, 2002; Wolf et al., 2011). An individual-based approach is therefore needed to account for resource competition among 
different sized trees within or between different PFTs. This size dependence may also have significant effect on the outcome of competition among different PFTs and their area fractions, and this will be explored in the future when CABLE is coupled to an appropriate DGVM.

Finally, fire plays a significant role in vegetation dynamics, and is ignored in this study. Previous studies argued that a large fraction of land area occupied by $\mathrm{C} 4$ grasses or savanna has the potential to become forest in the absence of fires (Bond et al., 2005). Some other factors, such as different variation of leaf maximum photosynthetic rate within the canopies of different forest functional types during the growing season (Wang et al., 2007; Bauerle et al., 2012), have not been taken into account in this study.

With the rapid growth of plant trait databases and advances in our theoretical understanding of the functioning of different plant traits, DGVMs have started to incorporate key plant traits and their functions (Scheiter \& Higgins, 2009; Falster et al., 2012; Wang et al., 2012; Pavlick et al., 2013; Scheiter et al., 2013; Fyllas et al., 2014; Reich et al., 2014; van Bodegom et al., 2014; Sakschewski et al., 2015). However, our theoretical understanding of many processes has yet to be tested at a global scale. Reich et al. (2014) demonstrated that incorporation of trait variation and corresponding differences in allocation led to better simulation of aggregate properties (LAI, GPP) and responses to warming in boreal forests, and Fisher et al. (2015) showed the importance of trait variation in determining competition between evergreen and deciduous trees in the eastern USA. Flowing from these works, ours is the first study to show that the dominance and co-dominance of different forest functional types globally can be simulated quite accurately if the variation and covariation of a few key plant traits are accounted for. We strongly recommend that future development of DGVMs should account for the variation and covariation of key plant traits.

\section{ACKNOWLEDGEMENTS}

This research was carried out during a visit by Xingjie $\mathrm{Lu}$ to CSIRO sponsored by the China Scholarship Council, and was completed during Xingjie Lu's post-doctoral fellowship funded by the CSIRO Office of Chief Executive.

\section{REFERENCES}

Allen, D.J. \& Ort, D.R. (2001) Impacts of chilling temperatures on photosynthesis in warm-climate plants. Trends in Plant Science, 6, 36-42.

Araujo, M.B. \& Peterson, A.T. (2012) Uses and misuses of bioclimatic envelope modeling. Ecology, 93, 1527-1539.

Bauerle, W.L., Oren, R., Way, D.A., Qian, S.S., Stoy, P.C., Thornton, P.E., Bowden, J.D., Hoffman, F.M. \& Reynolds, R.F. (2012) Photoperiodic regulation of the seasonal pattern of photosynthetic capacity and the implications for carbon cycling. Proceedings of the National Academy of Sciences USA, 109, 8612-8617.
Beer, C., Reichstein, M., Tomelleri, E. et al. (2010) Terrestrial gross carbon dioxide uptake: global distribution and covariation with climate. Science, 329, 834-838.

van Bodegom, P.M., Douma, J.C. \& Verheijen, L.M. (2014) A fully traits-based approach to modeling global vegetation distribution. Proceedings of the National Academy of Sciences USA, 111, 13733-13738.

Bonan, G.B., Levis, S., Sitch, S., Vertenstein, M. \& Oleson, K.W. (2003) A dynamic global vegetation model for use with climate models: concepts and description of simulated vegetation dynamics. Global Change Biology, 9, 1543-1566.

Bond, W.J. (1989) The tortoise and the hare - ecology of angiosperm dominance and gymnosperm persistence. Biological Journal of the Linnean Society, 36, 227-249.

Bond, W.J., Woodward, F.I. \& Midgley, G.F. (2005) The global distribution of ecosystems in a world without fire. New Phytologist, 165, 525-537.

Chabot, B.F. \& Hicks, D.J. (1982) The ecology of leaf life spans. Annual Review of Ecology and Systematics, 13, 229259.

Choat, B., Medek, D.E., Stuart, S.A., Pasquet-Kok, J., Egerton, J.J.G., Salari, H., Sack, L. \& Ball, M.C. (2011) Xylem traits mediate a trade-off between resistance to freeze-thaw-induced embolism and photosynthetic capacity in overwintering evergreens. New Phytologist, 191, 9961005.

Crepet, W.L. (1984) Advanced (constant) insect pollination mechanisms - pattern of evolution and implications vis-avis angiosperm diversity. Annals of the Missouri Botanical Garden, 71, 607-630.

DeFries, R.S. \& Hansen, M.C. (2009) ISLSCP II continuous fields of vegetation cover, 1992-1993. ISLSCP initiative II collection. Data set (ed. by F.G. Hall, Collatz, G., Meeson, B., Los, S., Brown De Colstoun, E. and Landis, D.). Oak Ridge National Laboratory Distributed Active Archive Center, Oak Ridge, TN. Available online at: http://daac.ornl. gov/.

Elith, J. \& Leathwick, J.R. (2009) Species distribution models: ecological explanation and prediction across space and time. Annual Review of Ecology Evolution and Systematics, 40, 677-697.

Enquist, B.J. \& Niklas, K.J. (2002) Global allocation rules for patterns of biomass partitioning in seed plants. Science, 295, 1517-1520.

Enquist, B.J., Norberg, J., Bonser, S.P., Violle, C., Webb, C.T., Henderson, A., Sloat, L.L. \& Savage, V.M. (2015) Scaling from traits to ecosystems: developing a general trait driver theory via integrating trait-based and metabolic scaling theories. Advances in Ecological Research, 52, 249-318.

Falster, D.S., Reich, P.B., Ellsworth, D.S., Wright, I.J., Westoby, M., Oleksyn, J. \& Lee, T.D. (2012) Lifetime return on investment increases with leaf lifespan among 10 Australian woodland species. New Phytologist, 193, 409-419.

Fisher, R.A., Muszala, S., Verteinstein, M., Lawrence, P., Xu, C., McDowell, N.G., Knox, R.G., Koven, C., Holm, J., Rogers, B.M., Spessa, A., Lawrence, D. \& Bonan, G. (2015) 
Taking off the training wheels: the properties of a dynamic vegetation model without climate envelopes, CLM4.5(ED). Geoscientific Model Development, 8, 3593-3619.

Fyllas, N.M., Gloor, E., Mercado, L.M., Sitch, S., Quesada, C.A., Domingues, T.F., Galbraith, D.R., Torre-Lezama, A., Vilanova, E., Ramirez-Angulo, H., Higuchi, N., Neill, D.A., Silveira, M., Ferreira, L., Aymard, G.A., Malhi, Y., Phillips, O.L. \& Lloyd, J. (2014) Analysing Amazonian forest productivity using a new individual and trait-based model (TFS v.1). Geoscientific Model Development, 7, 1251-1269.

Givnish, T.J. (2002) Adaptive significance of evergreen vs. deciduous leaves: solving the triple paradox. Silva Fennica, 36, 703-743.

Grime, J.P. (1977) Evidence for existence of three primary strategies in plants and its relevance to ecological and evolutionary theory. The American Naturalist, 111, 1169-1194.

Grime, J.P. \& Pierce, S. (2012) The evolutionary strategies that shape ecosystems. Wiley, Chichester.

Haxeltine, A. \& Prentice, I.C. (1996) BIOME3: an equilibrium terrestrial biosphere model based on ecophysiological constraints, resource availability, and competition among plant functional types. Global Biogeochemical Cycles, 10, 693-709.

Heide, O.M. (2003) High autumn temperature delays spring bud burst in boreal trees, counterbalancing the effect of climatic warming. Tree Physiology, 23, 931-936.

Kattge, J., Knorr, W., Raddatz, T. \& Wirth, C. (2009) Quantifying photosynthetic capacity and its relationship to leaf nitrogen content for global-scale terrestrial biosphere models. Global Change Biology, 15, 976-991.

Kattge, J., Diaz, S., Lavorel, S. et al. (2011) TRY - a global database of plant traits. Global Change Biology, 17, 29052935.

Kelley, D.I., Colin Prentice, I., Harrison, S.P., Wang, H., Simard, M., Fisher, J.B. \& Willis, K.O. (2012) A comprehensive benchmarking system for evaluating global vegetation models. Biogeosciences Discussions, 9, 15723-15785.

Kerkhoff, A.J., Enquist, B.J., Elser, J.J. \& Fagan, W.F. (2005) Plant allometry, stoichiometry and the temperaturedependence of primary productivity. Global Ecology and Biogeography, 14, 585-598.

Kikuzawa, K. (1991) A cost-benefit-analysis of leaf habit and leaf longevity of trees and their geographical pattern. The American Naturalist, 138, 1250-1263.

Kikuzawa, K. (1995) Leaf phenology as an optimal strategy for carbon gain in plants. Canadian Journal of BotanyRevue Canadienne de Botanique, 73, 158-163.

Kowalczyk, E.A., Stevens, L., Law, R.M., Dix, M., Wang, Y.P., Harman, I.N., Haynes, K., Srbinovsky, J., Pak, B. \& Ziehn, T. (2013) The land surface model component of ACCESS: description and impact on the simulated surface climatology. Australian Meteorological and Oceanographic Journal, 63, 65-82.

Lloyd, J. \& Taylor, J.A. (1994) On the temperaturedependence of soil respiration. Functional Ecology, 8, 315323.
McMurtrie, R.E. \& Dewar, R.C. (2011) Leaf-trait variation explained by the hypothesis that plants maximize their canopy carbon export over the lifespan of leaves. Tree Physiology, 31, 1007-1023.

Michaletz, S.T., Cheng, D.L., Kerkhoff, A.J. \& Enquist, B.J. (2014) Convergence of terrestrial plant production across global climate gradients. Nature, 512, 39.

Norberg, J., Swaney, D.P., Dushoff, J., Lin, J., Casagrandi, R. \& Levin, S.A. (2001) Phenotypic diversity and ecosystem functioning in changing environments: a theoretical framework. Proceedings of the National Academy of Sciences USA, 98, 11376-11381.

Pavlick, R., Drewry, D.T., Bohn, K., Reu, B. \& Kleidon, A. (2013) The Jena Diversity-Dynamic Global Vegetation Model (JeDi-DGVM): a diverse approach to representing terrestrial biogeography and biogeochemistry based on plant functional trade-offs. Biogeosciences, 10, 4137-4177.

Pianka, E.R. (1970) On $r$ and $K$ selection. The American Naturalist, 104, 592-597.

Prentice, I.C., Cramer, W., Harrison, S.P., Leemans, R., Monserud, R.A. \& Solomon, A.M. (1992) A global biome model based on plant physiology and dominance, soil properties and climate. Journal of Biogeography, 19, 117134.

Reich, P.B. (2012) Key canopy traits drive forest productivity. Proceedings of the Royal Society B: Biological Sciences, 279, 2128-2134.

Reich, P.B., Walters, M.B. \& Ellsworth, D.S. (1992) Leaf lifespan in relation to leaf, plant, and stand characteristics among diverse ecosystems. Ecological Monographs, 62, 365392.

Reich, P.B., Walters, M.B. \& Ellsworth, D.S. (1997) From tropics to tundra: global convergence in plant functioning. Proceedings of the National Academy of Sciences USA, 94, 13730-13734.

Reich, P.B., Rich, R.L., Lu, X.J., Wang, Y.P. \& Oleksyn, J. (2014) Biogeographic variation in evergreen conifer needle longevity and impacts on boreal forest carbon cycle projections. Proceedings of the National Academy of Sciences USA, 111, 13703-13708.

Richardson, A.D., Anderson, R.S., Arain, M.A. et al. (2012) Terrestrial biosphere models need better representation of vegetation phenology: results from the North American Carbon Program Site Synthesis. Global Change Biology, 18, 566-584.

Sakschewski, B., von Bloh, W., Boit, A., Rammig, A., Kattge, J., Poorter, L., Penuelas, J. \& Thonicke, K. (2015) Leaf and stem economics spectra drive diversity of functional plant traits in a dynamic global vegetation model. Global Change Biology, 21, 2711-2725.

Scheiter, S. \& Higgins, S.I. (2009) Impacts of climate change on the vegetation of Africa: an adaptive dynamic vegetation modelling approach. Global Change Biology, 15, 2224-2246.

Scheiter, S., Langan, L. \& Higgins, S.I. (2013) Next-generation dynamic global vegetation models: learning from community ecology. New Phytologist, 198, 957-969. 
Schimper, A.F.W., Fisher, W.R., Groom, P. \& Balfour, I.B. (1903) Plant-geography upon a physiological basis. Clarendon Press, Oxford.

Sellers, P.J., Bounoua, L., Collatz, G.J., Randall, D.A., Dazlich, D.A., Los, S.O., Berry, J.A., Fung, I., Tucker, C.J., Field, C.B. \& Jensen, T.G. (1996) Comparison of radiative and physiological effects of doubled atmospheric $\mathrm{CO}_{2}$ on climate. Science, 271, 1402-1406.

Sheffield, J., Goteti, G. \& Wood, E.F. (2006) Development of a 50-year high-resolution global dataset of meteorological forcings for land surface modeling. Journal of Climate, 19, 3088-3111.

Sitch, S., Smith, B., Prentice, I.C., Arneth, A., Bondeau, A., Cramer, W., Kaplan, J.O., Levis, S., Lucht, W., Sykes, M.T., Thonicke, K. \& Venevsky, S. (2003) Evaluation of ecosystem dynamics, plant geography and terrestrial carbon cycling in the LPJ dynamic global vegetation model. Global Change Biology, 9, 161-185.

Sitch, S., Huntingford, C., Gedney, N., Levy, P.E., Lomas, M., Piao, S.L., Betts, R., Ciais, P., Cox, P., Friedlingstein, P., Jones, C.D., Prentice, I.C. \& Woodward, F.I. (2008) Evaluation of the terrestrial carbon cycle, future plant geography and climate-carbon cycle feedbacks using five dynamic global vegetation models (DGVMs). Global Change Biology, 14, 2015-2039.

Taylor, K.E. (2001) Summarizing multiple aspects of model performance in a single diagram. Journal of Geophysical Research-Atmospheres, 106, 7183-7192.

Wang, Y.P., Baldocchi, D., Leuning, R., Falge, E. \& Vesala, T. (2007) Estimating parameters in a land-surface model by applying nonlinear inversion to eddy covariance flux measurements from eight FLUXNET sites. Global Change Biology, 13, 652-670.

Wang, Y.P., Law, R.M. \& Pak, B. (2010) A global model of carbon, nitrogen and phosphorus cycles for the terrestrial biosphere. Biogeosciences, 7, 2261-2282.

Wang, Y.P., Kowalczyk, E., Leuning, R., Abramowitz, G., Raupach, M.R., Pak, B., van Gorsel, E. \& Luhar, A. (2011) Diagnosing errors in a land surface model (CABLE) in the time and frequency domains. Journal of Geophysical Research-Biogeosciences, 116, G01034.

Wang, Y.P., Lu, X.J., Wright, I.J., Dai, Y.J., Rayner, P.J. \& Reich, P.B. (2012) Correlations among leaf traits provide a significant constraint on the estimate of global gross primary production. Geophysical Research Letters, 39, L19405.

Warming, E., Balfour, I.B., Groom, P. \& Vahl, M. (1909) Oecology of plants; an introduction to the study of plantcommunities. Clarendon Press, Oxford.

Westoby, M., Falster, D.S., Moles, A.T., Vesk, P.A. \& Wright, I.J. (2002) Plant ecological strategies: some leading dimensions of variation between species. Annual Review of Ecology and Systematics, 33, 125-159.

Wolf, A., Field, C.B. \& Berry, J.A. (2011) Allometric growth and allocation in forests: a perspective from FLUXNET. Ecological Applications, 21, 1546-1556.
Wright, I.J., Reich, P.B., Westoby, M. et al. (2004) The worldwide leaf economics spectrum. Nature, 428, 821-827.

Zhang, H.Q., Pak, B., Wang, Y.P., Zhou, X.Y., Zhang, Y.Q. \& Zhang, L. (2013a) Evaluating surface water cycle simulated by the Australian community land surface model (CABLE) across different spatial and temporal domains. Journal of Hydrometeorology, 14, 1119-1138.

Zhang, Q., Wang, Y.P., Pitman, A.J. \& Dai, Y.J. (2011) Limitations of nitrogen and phosphorus on the terrestrial carbon uptake in the 20th century. Geophysical Research Letters, 38.

Zhang, Q., Pitman, A.J., Wang, Y.P., Dai, Y.J. \& Lawrence, P.J. (2013b) The impact of nitrogen and phosphorous limitation on the estimated terrestrial carbon balance and warming of land use change over the last 156 yr. Earth System Dynamics, 4, 333-345.

Zhang, Q., Wang, Y.P., Matear, R.J., Pitman, A.J. \& Dai, Y.J. (2014) Nitrogen and phosphorous limitations significantly reduce future allowable $\mathrm{CO} 2$ emissions. Geophysical Research Letters, 41, 632-637.

Zhang, X.Y., Friedl, M.A., Schaaf, C.B. \& Strahler, A.H. (2004) Climate controls on vegetation phenological patterns in northern mid- and high latitudes inferred from MODIS data. Global Change Biology, 10, 1133-1145.

Zhang, X.Y., Friedl, M.A., Schaaf, C.B., Strahler, A.H. \& Liu, Z. (2005) Monitoring the response of vegetation phenology to precipitation in Africa by coupling MODIS and TRMM instruments. Journal of Geophysical Research-Atmospheres, 110, D12103.

Zhang, X.Y., Friedl, M.A. \& Schaaf, C.B. (2006) Global vegetation phenology from Moderate Resolution Imaging Spectroradiometer (MODIS): evaluation of global patterns and comparison with in situ measurements. Journal of Geophysical Research-Biogeosciences, 111, G04017.

Zhou, X.Y., Zhang, Y.Q., Wang, Y.P., Zhang, H.Q., Vaze, J., Zhang, L., Yang, Y.H. \& Zhou, Y.C. (2012) Benchmarking global land surface models against the observed mean annual runoff from 150 large basins. Journal of Hydrology, 470, 269-279.

\section{SUPPORTING INFORMATION}

Additional supporting information may be found in the online version of this article at the publisher's web-site:

Appendix S1 Global parameter sensitivity analysis Appendix S2 Statistics of the four plant traits.

Appendix S3 Estimates of PFT area fraction from ISLSCP data product.

Appendix S4 Leaf phenology.

Appendix S5 Description of the phenomenology model.

Table S1 Biogeochemical parameter definitions.

Table S2 Biogeochemical parameter ranges. In the table, PFT-dependent parameters mean parameters that use different ranges for different plant functional types (PFTs). Common value parameters mean parameters that share the same range with all PFTs. Soil classification dependent parameters mean parameters that have different ranges for 
different soil types. The abbreviations of PFTs in the Table are defined as followed: ENF (Evergreen Needleleaf Forest), EBF (Evergreen Broadleaf Forest) and DBF (Deciduous Broadleaf Forest).

Figure S1 Means $\left(\mu_{\mathrm{i}}\right)$ and standard deviations $\left(\sigma_{\mathrm{i}}\right)$ of the elementary effects of 59 model parameters on annual net primary production (NPP) for (a) evergreen needleleaf forest (ENF); (b) evergreen broadleaf forest (EBF); (c) deciduous broadleaf forest (DBF).

Table S3 Mean $\mu(\mathrm{x})$, standard deviation $\sigma(\mathrm{x})$ and correlation coefficient (Corr) of the $\log 10$ transformed leaf age $\left(\tau_{1}\right)$, leaf nitrogen concentration $(n)$ and non-log10 transformed basal maintenance respiration rate at $10^{\circ} \mathrm{C}(r)$, leaf allocation fraction $\left(\mathrm{a}_{\mathrm{L}}\right)$.

Figure S2 The statistics (maximum, minimum, average, upper and lower quartiles) of ensemble samples of four plant traits: a) $C N_{l}$ : leaf $\mathrm{C}$ to $\mathrm{N}$ ratio, b) $\tau_{\mathrm{l}}$ : leaf life span, c) $\mathrm{a}_{\mathrm{L}}$ : fraction of NPP allocated to leaf and d) $r$ : basal respiration rate coefficient of wood $\left(r_{w}\right)$ and root $\left(r_{r}\right)$. Here we assume that basal respiration rates of wood and root are equal.

Figure S3 (a) Global variations in forested area cover fractions from International Satellite Land Surface Climatology Project II Continuous Fields of Vegetation Cover (ISLSCP data) (DeFries \& Hansen, 2009) (cells only with the land area cover fraction by forests over $50 \%$ are selected); (b) Latitudinal variation in land area cover fractions for each of the three major forest types (ISLSCP data): evergreen needleleaf forest (ENF) (solid grey line), evergreen broadleaf forest (EBF) (dashed grey line), or deciduous broadleaf forest (DBF) (solid black line).

Figure S4 Estimates of PFT land area cover fraction for: a) Evergreen Needleleaf Forest (ENF), Evergreen Broadleaf
Forest (EBF), Deciduous Needleleaf Forest (DNF) and Deciduous Broadleaf Forest (DBF).

Figure S5. Latitudinal variation in leaf phenology of deciduous broadleaf forest (DBF) (a) Variation in the day of the year defining the four key phenological phases: start of green-up (black solid line), end of green-up (dotted grey line), start of leaf fall (solid grey line) or end of leaf fall (dashed grey line); (b) Latitudinal variation in the length of the growing season (number of days from the start of greenup to the end of leaf fall).

Figure S6 Forest PFT land area cover fractions varied with mean annual surface temperature. The linear regression with mean annual surface air temperature are calculated for three PFTs as well (Blue for ENF, green for EBF and yellow for $\mathrm{DBF})$.

\section{BIOSKETCH}

Xingjie Lu holds a PhD from the College of Global Change and Earth System Science of Beijing Normal University. He is a post-doctoral fellow with interests in plant traits, the global land carbon cycle and data assimilation.

Author contributions: Y.P.W. conceived the idea and discussed with X.L., I.J.W. and P.B.R. supplied the global plant trait data, X.L. and Y.P.W. implemented the CABLE modelling. All co-authors contributed to the discussion and write-up of the paper.

Editor: Dr. Brian Enquist 